\title{
Women's views and experiences of accessing vaccination in pregnancy during the COVID-19 pandemic: A multi-methods study in the United Kingdom
}

\author{
Authors \& Affiliations
}

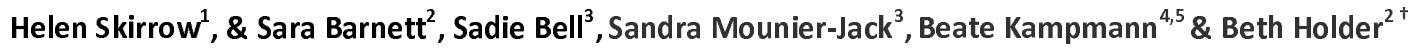

1. Department of Primary Care and Public Health, School of Public Health, Imperial College London, United Kingdom.

2. Institute of Reproductive and Developmental Biology, Department of Metabolism, Digestion and Reproduction, Imperial College London, United Kingdom

3. Department of Global Health and Development, Faculty of Public Health and Policy, London School of Hygiene \& Tropical Medicine, 15-17 Tavistock Place, London, WC1H 9SH, United Kingdom

4. The Vaccine Centre, Faculty of Infectious and Tropical Diseases, London School of Hygiene \& Tropical Medicine, Keppel Street, Bloomsbury, London, WC1E 7HT, United Kingdom

5. Vaccines and Immunity Theme, MRC Unit The Gambia at LSHTM, Atlantic Boulevard, PO Box 273, Banjul, The Gambia.

${ }^{\dagger}$ Corresponding author:

Dr. Beth Holder

Imperial College London

Institute of Reproductive and Developmental Biology

Hammersmith Campus

London

W12 OHS

b.holder@imperial.ac.uk 
2 Abstract:

4 Background: COVID-19 changed access to healthcare, including vaccinations, in the United Kingdom (UK). This study 5 explored UK women's experiences of accessing pertussis vaccination during pregnancy and infant vaccinations during 6 COVID-19.

7 Methods: An online cross-sectional survey was completed, between $3^{\text {rd }}$ August- $11^{\text {th }}$ October 2020 , by 1404 women 8 aged $16+$ years who were pregnant at some point after the first UK lockdown from March $23^{\text {rd }}, 2020$. Ten follow-up 9 semi-structured interviews were conducted.

10 Results: Most women surveyed were pregnant (65.7\%) and a third postnatal (34.3\%). Almost all women (95.6\%) were 11 aware that pertussis vaccination is recommended in pregnancy. Most pregnant (72.1\%) and postnatal women (84.0\%) 12 had received pertussis vaccination; however, access issues were reported.

13 Over a third (39.6\%) of women had a pregnancy vaccination appointment changed. COVID-19 made it physically difficult 14 to access pregnancy vaccinations for one fifth $(21.5 \%)$ of women and physically difficult to access infant vaccinations for 15 almost half of women (45.8\%). Nearly half of women $(45.2 \%)$ reported feeling less safe attending pregnancy 16 vaccinations and over three quarters $(76.3 \%)$ less safe attending infant vaccinations due to COVID-19. The majority 17 (94.2\%) felt it was important to get their baby vaccinated during COVID-19.

18 Pregnant women from ethnic-minorities and lower-income households were less likely to have been vaccinated. 19 Minorityethnicity women were more likely to report access problems and feeling less safe attending vaccinations for 20 both themselves and their babies.

21 Qualitative analysis found women experienced difficulties accessing antenatal care and relied on knowledge from 22 previous pregnancies to access vaccines in pregnancy.

23 Conclusion: During the ongoing and future pandemics, healthcare services should prioritise equitable access to routine 24 vaccinations, including tailoring services for ethnic-minority families who experience greater barriers to vaccination.

- Access to pregnancy vaccines in the United Kingdom was disrupted by the COVID-19 pandemic.

- UK women reported difficulties in physically accessing vaccine appointments and feeling less safe accessing vaccine appointments for themselves when pregnant and for their babies during COVID19 , with women from ethnic minorities in the UK were more likely to report difficulties.

- Vaccine services must ensure equitable access to vaccine appointments during the ongoing COVID19 pandemic including tailoring services for lower income and ethnic minority families. 
Background:

37 The COVID-19 pandemic has affected the delivery and uptake of routine vaccination programmes for pregnant

38 women and children worldwide (1-6) increasing the risk of infectious disease outbreaks (7). In the United Kingdom

39 (UK), despite routine vaccination programmes for pregnant women and children being prioritised (8) by the National

40 Health Service (NHS), changes to primary-care (9) and maternity services (10) during the pandemic dis rupted

41 vaccination programme $(7,11)$. For example, decreased numbers of measles, mumps and rubella (MMR) vaccines were

42 delivered after the start of the first national lockdown in March 2020 in England (12). Declines in childhood

43 vaccination in England recovered over the summer of 2020; however, overall childhood vaccine uptake in England for

442020 was lower compared to previous years (13). In the UK, pregnant women are routinely advised to be vaccinated

45 against pertussis (whooping cough) between 16 and 32 weeks of pregnancy, as well as seasonal influenza. Pertussis

46 vaccine uptake for pregnant women in England eligible to be vaccinated after the first national lockdown in 2020 was

$474.1 \%$ lower than the same period in 2019; the lowest it has been since 2016 (14).

48 Traditionally, vaccinations are delivered in primary care via general practices (GPS) in the UK; however some

49 hospital-based antenatal clinics also offer vaccines to pregnant women (15). During the first national lockdown the

50 public were advised to 'stay at home' and avoid attending healthcare settings unless necessary. A reduction in primary

51 care use was observed (16) and routine vaccines services adapted in primary care (17). The shift to more remote

52 consultations and reductions in face-to-face appointments $(9,10)$, may have reduced women's access to vaccines.

Work by co-authors Bell et al. found that UK parents felt confused about whether routine childhood vaccine

54 services were still running normally during the first national lockdown (18). Pregnant women were classified as at

55 increased risk from COVID-19 and advised by the UK government to adhere closely to social distancing guidance (19).

56 These messages may have therefore affected pregnant women's willingness to attend healthcare facilities for

57 vaccination, as seen for childhood vaccination $(3,18)$. Two qualitative studies by Anderson et al have reported that

58 pregnant women felt confused by the risk COVID-19 represented to them and that some women also factored the risk

59 of COVID-19 when considering attending routine pregnancy vaccine appointments $(20,21)$. There has yet to be a

60 detailed report on the impact of the COVID-19 pandemic on women's access to routine pregnancy vaccines.

61 This multi-methods study investigates the impact of the COVID-19 pandemic on women's awareness, and

62 acceptance of pertussis vaccine in pregnancy and access to pertussis vaccine and childhood vaccines in the UK. 
medRxiv preprint doi: https://doi.org/10.1101/2021.09.14.21263505; this version posted September 17, 2021. The copyright holder for this preprint (which was not certified by peer review) is the author/funder, who has granted medRxiv a license to display the preprint in perpetuity.

It is made available under a CC-BY 4.0 International license .

64

65

66

67

68

69

70

71

72

73

74

\section{Survey Content}

\section{Ethical approval}

86 This study was approved by Imperial College Research Ethics Committee (ICREC) (Ref: 20IC6188).

87
The survey included questions about pertussis vaccine awareness and uptake during pregnancy. Questions also asked about access to antenatal care and the pertussis vaccination during the pandemic, including where they would have preferred to receive their vaccine and what sources of information on pregnancy vaccines they would prefer. Questions also asked about whether the COVID-19 pandemic had restricted their physical access to vaccines or made them feel less safe getting themselves and their baby vaccinated. Women were also asked whether they felt it was important to have their baby vaccinated during the pandemic. See supplementary file A for full survey.

\section{Survey Recruitment}

The survey was advertised and promoted using Facebook with a landing page and paid advertising using

Facebook's ad manager which crossposts to Instagram. The three adverts had a combined reach of 46,146, with 1,573 
medRxiv preprint doi: https://doi.org/10.1101/2021.09.14.21263505; this version posted September 17, 2021. The copyright holder for this preprint (which was not certified by peer review) is the author/funder, who has granted medRxiv a license to display the preprint in perpetuity.

It is made available under a CC-BY 4.0 International license .

91 post engagements and 1,394 link clicks. Related organisations on Facebook were also contacted individually by study

92 researchers, including pregnancy yoga and birth preparation classes, breastfeeding support groups and toddler groups.

93 The survey was shared and distributed via the research team's personal twitter accounts, including linking to other

94 researchers and organisations with maternal and vaccine uptake interests. Finally, the survey was also promoted via

95 some Maternity Voices Partnerships (23) who were e-mailed and invited to share the survey, and via a post on the

96 website Mumsnet.

97 Eligible participants were required to have been pregnant at some point between the start of the first UK

98 lockdown (from 23rd March 2020) and the time of survey completion, to be resident in the UK, and to be aged 16 years

99 or over. The survey was live from $3^{\text {rd }}$ August until $11^{\text {th }}$ October 2020 . The online survey was prefaced by an information

100 page explaining the study, and how the data was to be used (Supplementary material A). Participants were informed

101 that by taking part in the survey they agreed for their responses to be used for research purposes. Participants were

102 required to confirm (by tick-box) at the start of the survey that they met the eligibility criteria and that they consented

103 to participate in the survey.

104

105

Survey Analysis

106

Descriptive statistics of survey respondents were reported, and statistical analysis undertaken using Stata

107 (version-16). Binary answers, including awareness and uptake of pertussis vaccination, were compared by age group,

108 household income, ethnicity, region and country of the United Kingdom using Pearson's chi-squared statistic.

For responses to questions on Likert scales (e.g., where responses were scored on a scale of 'Strongly agree,

110 somewhat agree, neither agree nor disagree, somewhat disagree, strongly disagree and not/applicable'), stepwise

111 logistic regression was undertaken to determine factors associated with the responses. To facilitate analysis with the

112 number of responses obtained, the $<20 y$ group was combined with the next age bracket to form $<25 y$ age bracket, the

113 ten income groups were combined pairwise to form five groups, and ethnicity was dichotomised into 'White' (i.e.,

114 White British, White Irish and White Other participants) and 'Ethnic minorities' (i.e., Black, Asian, Chinese, Mixed

115 ethnicities or Other ethnicities). A p value of less than 0.05 was considered statistically significant.

\section{Semi-structured interviews}


118 their contact details. A selection of participants who had left their contact details were contacted by SBa. Participants

119 were purposively selected to prioritise women: 1) from ethnic-minority backgrounds, due to lower representation

120 among survey respondents; 2) who were pregnant when surveyed, due to their proximity to their pregnancy experience

121 compared to those that had already had their babies ; 3) who had not completed the open text responses. Informed

122 written and verbal consent was obtained from participants. The participant information sheet and consent form were

123 provided by e-mail (Supplementary material B). Interviews lasted approximately 30 minutes and were conducted over

124 the telephone and/or using Microsoft Teams and were recorded with permission of the participant. Interviews were

125 conducted by SBa and HS using a topic guide. The topic guide was developed based on the questionnaire

126 (Supplementary material C). The interviews took place between the $7^{\text {th }}$ and 16 th of December 2020.

\section{Qualitative analysis}

129 Qualitative interviews and free-text survey responses were analysed thematically by SBa using the stages outlined 130 by Braun and Clarke: data familiarisation, coding and theme identification and refinement (24). To enhance the rigour 131 of the analysis, coding approaches and subsequent theme generation and refinement was discussed between HS, SBa, 132 SBe and $\mathrm{BH}$.

133 Results

\section{Demographics}

135 In total, our recruitment strategy led to 1526 survey click throughs. 122 responses were excluded because they 136 were pilot responses or incomplete responses, leaving 1,404 responses. Available demographic details are summarised

137 in Supplementary Figure 1. Most women were 30-34 years ( $n=548,39.0 \%$; Supplementary Figure 1A), and White British

138 ( $n=1072,76.4 \%$; Supplementary Figure 1B). Most women were pregnant at the time of taking the survey $(n=922,65.7 \%$;

139 Supplementary Figure 1C). Median household annual income was $f 45,999-54,999$ (Supplementary Figure 1D) and most

140 women worked full-time ( $n=848,60.4 \%$; Supplementary Figure 1E). Most women either had no other children $(n=517$,

$14136.8 \%$ ) or one child ( $n=524,37.3 \%$; Supplementary Figure 1F). The majority were living in England ( $n=1289,91.8 \%$;

142 Supplementary Figure $1 \mathrm{G}$ ), and the highest proportion were from London and the South-West (Supplementary Figure

$1431 \mathrm{H})$. Women that had given birth by the time of survey completion had mostly delivered between April and August

1442020 (Supplementary Figure 1I). Those who were pregnant at the time of survey completion ranged from 5 to 41 
145 weeks' gestation, with 34 weeks being the most frequent gestation ( $n=50$; Supplementary Figure $1 \mathrm{~J})$. The characteristics

146 of the women interviewed are shown in Supplementary Table 1.

148 Findings

149 Findings from the quantitative survey analysis, and the qualitative analysis of the free-text survey responses

150 and the interviews are presented together. To support findings the overarching themes from the qualitative analysis,

151 with supporting quotes, are provided in Table 1.

153 Awareness of pertussis vaccine recommendation in pregnancy

154 The majority of women $(95.6 \%, n=1338)$ - including those pregnant and those postnatal - were aware that 155 pertussis vaccination is recommended in pregnancy (Figure 1A). Women with an annual household income below

$156 f 25,000$ were more likely to be unaware $(p=0.02)$ of pertussis vaccination being recommended in pregnancy (Figure

157 1B). Awareness of pertussis vaccine in pregnancy did not otherwise vary by age, ethnicity or geographically (Table 2).

158 Qualitative analysis found that women's awareness of the pertussis vaccination often came from their own prior

159 personal pregnancy experiences (Table 1).

Pertussis vaccine information for pregnant women during COVID-19

163 and preferred face-to-face information above other types of information such as leaflets (Figure 2B). Qualitative

164 analysis found women commonly reported a lack of opportunity to get information about vaccines in pregnancy,

165 associated with wider issues around a lack of general information provided in pregnancy, compared to their

166 experiences of previous pregnancies prior to lockdown: "Communication with healthcare professionals

167 (midwives/GP/antenatal) has been awful during this pregnancy compared to 4 years ago..... The lack of contact and care

168 from health professionals is extremely concerning. A leaflet does not replace a face-to-face appointment when a person

169 is in a vulnerable physical and mental condition".

Uptake of pertussis vaccine in pregnancy during COVID-19

172 Uptake of pertussis vaccine during pregnancy among women who were currently pregnant was $72.1 \%(n=624)$

173 and among new mothers was $89.1 \%(n=408)$ (Supplementary Table 2). Among women who were currently pregnant 
174 and unvaccinated against pertussis $(n=241)$ the majority were in the first or second trimester $(82.6 \%, n=199)$

175 (Supplementary Table 2) and most were intending to be vaccinated $(84.6 \%, n=204$ ) (Supplementary Table 3).

Among women who were pregnant when surveyed but unaware that pertussis vaccination was recommended

177 ( $n=46)$, when asked 'Now you know that this vaccine is recommended in pregnancy, do you think you will get

178 vaccinated?' most (76\%) answered that they would or were leaning towards being vaccinated (Supplementary Table 4).

Of women vaccinated against pertussis in a previous pregnancy $(n=188)$ most were also vaccinated in

180 this pregnancy ( $n=181$, Figure 3 ). Only $6.9 \%$ of women changed to not being vaccinated in pregnancy. $30 \%$ of women

181 who were unvaccinated in their most recent previous pregnancy were vaccinated in this pregnancy during COVID-19

182 (Figure 3).

183 Qualitative analysis found that some women felt that vaccination in pregnancy during the pandemic was even

184 more important than ever as a motivator for getting vaccinated: "I have always believed in vaccines but covid has made

185 me even more so." However, women also considered the risk of COVID-19 when attending vaccine appointments such

186 as: "The only thing that's made me feel unsafe is going to the hospital for the tdap (pertussis vaccine) and being in that

187 environment". Some women also described feeling that their trust in either vaccines or the wider medical

188 establishment was influenced by the pandemic for example one women said, "This pandemic had made me less trusting

189 of the medical and political establishment". One woman who self-reported as Pakistani described how social media had

190 led her to believe that "COVID vaccine amongst others is used to control the black and Asian population and can lead to

191 infertility".

192

193 Predictors of pertussis vaccination uptake in pregnancy during COVID-19

Pregnant women in the first and second trimester had lower vaccine uptake compared to women in their third

195 trimester (Sup plementary Table 2) however, most planned to be vaccinated (Supplementary Table 3). Therefore, to

196 look at predictors of vaccination among pregnant women, we looked just at those who were in their third trimester.

197 Women in their third trimester who were from an ethnic-minority (excluding White ethnic-minorities) were more likely

198 to be unvaccinated compared to White ethnicity women ( $p=0.041$; Table 3$)$. Those aged under 25 years were also more

199 likely to be unvaccinated compared to those aged $30-34$ years $(p=<0.0001$; Table 3 ). Income did not predict vaccine

200 uptake in these women $(p=0.884 ;$ Table 3$)$. Among new mothers, women from ethnic minorities $(p=0.001)$ were more

201 likely to be unvaccinated compared to women of White ethnicity (Table 3). In this group, living in households with an 
202 income below $£ 25,000$ was also associated with higher likelihood to be unvaccinated $(p=0.02 ;$ Table 3 ). In these

203 women, age did not predict vaccine uptake ( $p>0.05$; data not shown).

204 Multivariate logistic regression that considered ethnicity, age and income, found that for women in their third

205 trimester, most age groups were more likely to be unvaccinated compared to the most common 30-34-year age group,

206 and age and ethnicity were no longer significant predictors. In women who had already delivered, being unvaccinated

207 was still associated with being from an eth nic-minority $(p=<0.001)$ and a lower-income household $(<f 25,000, p=0.012$;

208 Table 4).

209 Among unvaccinated pregnant women $(n=87), 25 \%(n=22)$ answered that 'they wanted to be vaccinated but

210 didn't because of the COVID-19 pandemic' (Supplementary Table 5). Among unvaccinated women who had already

211 delivered ( $n=47)$, only $2 \%(n=1)$ answered that they 'didn't want to be vaccinated', $43 \%$ ( $n=20)$ 'didn't know about the

212 vaccine' and $21 \%(n=10)$, answered that 'they wanted to be vaccinated but didn't because of the COVID-19 pandemic'

213 (Supplementary Table 5).

214

\section{Access to pregnancy vaccine appointments during COVID-19}

216 Among the $>1,000$ women surveyed the majority (62\%) had experienced a GP appointment for their pregnancy

217 being changed, cancelled or postponed due to COVID-19, with appointments most commonly being changed to phone

218 or online appointments (53.3\%) (Table 5). There were more reports of appointments being postponed or cancelled by

219 the GP $(10.8 \%$ and $16.2 \%$ respectively), compared to then being postponed or cancelled by patients $(2.1 \%$ and $1.1 \%$

220 respectively). Over a third of women (39.6\%) surveyed reported that their GP appointment for a vaccine was changed,

221 postponed or cancelled during the pandemic. Only 7.5\% of women reported that a vaccine hospital appointment had

222 been changed. Nearly half (42.9\%) reported that a hospital appointment for another reason had been changed,

223 postponed or cancelled. Most of these (33.2\%) were changed to phone or online appointments (Table 5).

224 Qualitative analysis found that the onus was on the women to organise and push to have their vaccines in

225 pregnancy and first-time parents who didn't have the prior knowledge about vaccines in pregnancy found it particularly

226 difficult. For example, one woman said: "It is a good job I have been pregnant before and understood I required the

227 whooping cough. My midwife has given me no communication".

229 Physical access and safety attending pregnancy vaccine appointments 
231 physical access to pregnancy vaccines (Figure $4 \mathrm{~A})$. Nearly half of women $(45.2 \%, \mathrm{n}=564)$ strongly agreed $(12.8 \%)$ or

232 somewhat agreed (32.4\%) that the pandemic had made them feel less safe attending their pregnancy vaccine

233 appointments (Figure 4B).

234 We next looked at the predictors of the responses to the questions about physical restriction and feeling safe

235 getting pregnancy vaccines. Women who were from ethnic minorities other than White were more likely to report that

236 the pandemic had restricted their physical access (Figure 4A, $p=0.009$ ) and that they felt less safe attending for

237 pregnancy vaccines (Figure 4B, $\mathrm{p}=0.015$ ), compared to women of White ethnicities. Women from lower-income

238 households $(<£ 25,000)$ were more likely to have felt their access to pregnancy vaccine appointments was restricted or

239 felt less safe attending vaccine appointments due to COVID-19 compared to the highest income households (Figures $4 \mathrm{~A}$

$240 \& 4$ B). Women aged under 25 years were also more likely to have felt their access to pregnancy vaccine appointments

241 was restricted (Figure 4A);however, they did not report a higher feeling less safe attending vaccine appointments due

242 to COVID-19 (Figure 4B).

243 Qualitative analysis also found that women reported confusion and difficulties in booking vaccine

244 appointments in pregnancy and a lack of available information about pregnancy vaccines during COVID-19. This meant

245 some women experienced being vaccinated later in pregnancy than recommended. For example, "I got conflicting

246 advice about where I could get the whooping cough vaccine...... After quite a lot of attempts to contact various settings I

247 managed to book.....and have it in a community setting although it was later than the recommended time for the

248 vaccine to work effectively." Confusion was often related to wider disruption to all antenatal care appointments and

249 not specific to pregnancy vaccine appointments. Women described the stress and anxiety caused by the move from

250 face-to-face to remote appointments in antenatal care and COVID-19 protocols: "appointments were on the phone or

251 then when you did have to go in, you had to like follow strict procedures. So yeah, it was actually quite stressful to be

252 honest".

253

Physical access, safety and importance of vaccinating their baby during COVID-19

The majority of women $(94.2 \%, n=1,106)$ felt that it was important to get their baby vaccinated during the

COVID-19 pandemic (Figure 5A, 85.9\% strongly and 8.3\% somewhat agreeing). The majority $(76.3 \%, n=893)$ of women 
258 pandemic (Figure 5A). Nearly half (45.8\%) of women strongly agreed or somewhat agreed that the COVID-19 pandemic

259 would make it physically difficult to get their baby vaccinated (Figure 5A).

260 We next performed multivariate analyses to investigate predictors of responses to infant vaccination,

261 considering ethnicity, age and income. With age and income considered, belonging to an ethnic-minority was predictive

262 of women feeling that they would find it physically difficult to access vaccines for their babies ( $p=0.001)$, feeling less

263 safe accessing vaccines for their baby $(p=0.001)$ and reporting lower importance to vaccinating their baby during the

264 pandemic $(p=<0.001)$ (Table 6$)$. Women aged under 25 years were more likely to feel less safe getting their baby

265 vaccinated $(p=0.001)$ (Table 6$)$. Women from lower-income households $(<f 45,000)$ were more likely to report lower

266 importance for vaccinating their baby during the pandemic compared to the highest income group. Income was not a

267 predictor in multi-variate analysis for feeling less safe or finding getting their baby vaccinated during COVID-19 was

268 physically harder (Table 6).

269 Women who had answered that the COVID-19 pandemic had made their access to vaccines in pregnancy

270 physically difficult were also likely to report that the COVID-19 pandemic meant they felt it would be physically difficult

271 to get their baby vaccinated (Figure 5B). Women's responses to feeling safe getting themselves vaccinated in pregnancy

272 or getting their babies vaccinated were less aligned (Figure 5C).

273

\section{Delivery of pertussis vaccines during and prior to the COVID-19 pandemic}

275 Of those vaccinated in pregnancy, most women had been vaccinated at their GP ( $n=637,61.8 \%$ ), followed by a

276 hospital antenatal care setting ( $n=316,30.7 \%)$ (Supplementary Table 6). Among unvaccinated pregnant women, the

277 majority were similarly planning to attend either their $\mathrm{GP}(\mathrm{n}=114,55.9 \%)$ or a hospital antenatal care setting ( $\mathrm{n}=59$,

$278 \quad 28.9 \%$, supplementary Table 7).

279 Vaccination location varied by country and English region (Supplementary Figures 2A and 2B). More Scottish

280 women were vaccinated in a hospital antenatal setting $(42.9 \%, n=18)$, followed by English women $(31.6 \%, n=298)$,

281 whereas no Welsh nor Northern Irish women were vaccinated in hospital (Supplementary Figure 2A, $p=<0.001$ ). In

282 Wales and Northern Ireland, vaccination by GPs was far higher; $92.1 \%$ and $100 \%$ in Wales and NI respectively. Location

283 of vaccination also varied across regions of England (Supplementary Figure $2 \mathrm{~B}$ ) with $65.5 \%$ ( $\mathrm{n}=38$ ) of women in the East

284 Midlands vaccinated at antenatal hospital settings compared to only $2.3 \%(n=1)$ of women in the North-East region of

285 the UK, $(p=<0.001)$. Vaccination in antenatal community settings was highest in the North-East and North-West 
It is made available under a CC-BY 4.0 International license.

286 England. Women's preference for where they wanted to be vaccinated during pregnancy in the COVID-19 pandemic

287 showed higher preference for GPs and community antenatal settings (Supplementary Figure 2C).

289 vaccinated at a GP surgery during their COVID-19 pregnancy (Supplementary Figure 2D). The main change in location

290 was that $46 \%(n=53)$ of women who were vaccinated at a hospital antenatal appointment during COVID-19 had been

291 vaccinated at a GP surgery in their previous pregnancy (Supplementary Figure 2D).

292

\section{Travel to healthcare settings during COVID-19}

Given government advice on travel and public transport use during the pandemic, women were asked how

295 they usually travelled to various health care providers, before and during the pandemic. Travel by public transport to

296 GPs, pharmacies and antenatal appointments all decreased during the pandemic (Supplementary Figure 3A); 40.1\%

297 women travelled using public transport to antenatal appointments before the pandemic, which dropped to only $6.2 \%$

298 during the pandemic (Supplementary Figure 3B). Public transport to attend antenatal appointments varied regionally,

299 pre and post COVID-19 with women from London reporting highest pre-pandemic public transport use (40.1\%)

300 (supplementary Figure 1C) and also the greatest change (84.5\% drop: supplementary Figures 3D \& 3E).

\section{Discussion}

303

304

Despite finding high awareness and uptake among the over 1000 women surveyed, we found that women's

306 access to pertussis vaccination during the pandemic was disrupted. Qualitative findings suggest that women's previous

307 knowledge and pregnancy experiences before COVID-19 highly influenced their vaccination experiences. Women

308 described having to be proactive in getting vaccine appointments and confusion about how to access antenatal care.

309 Nearly two thirds of women surveyed reported that their antenatal appointments had been changed due to COVID-19,

310 most commonly to remote consultations.

311 The majority (95.6\%) of women were awa re that the pertussis vaccine is recommended in pregnancy. We

312 found higher pertussis vaccine uptake (84\%) among women surveyed who had already delivered their baby compared

313 to national pertussis vaccine uptake estimates during the same time period (14). Among currently pregnant women

314 surveyed uptake was lower (72.1\%); however, the majority of pregnant women who were unvaccinated were in the 
It is made available under a CC-BY 4.0 International license .

315 first and second trimester and were planning to get vaccinated, so this lower uptake is likely due to their gestation

316 when completing the survey.

317 The women surveyed and interviewed felt that their antenatal care had been impacted negatively by the

318 pandemic including perceiving a lack of information about how to get vaccinated in pregnancy. The lack of face-to-face

319 appointments was mentioned by different women as a key barrier to accessing information and advice from healthcare

320 professionals. Appointments were described as rushed and women found being pregnant during COVID-19 stressful.

321 Our survey findings suggest that vaccination experiences varied in the UK by region, ethnicity, income, age and

322 was also influenced by their previous pregnancies. Women from ethnic minorities were less likely to have been

323 vaccinated in pregnancy and were also more likely to report feeling less safe attending vaccine appointments and that

324 their access to vaccine appointments had been physically restricted due to the pandemic for them and their babies.

325 Women from lower-income households were less likely to be aware of pertussis vaccine recommendation and remain

326 unvaccinated by the time they delivered their baby. Younger women below the age of 25 were less likely to have been

327 vaccinated in pregnancy, which may reflect them being pregnant for the first time as our qualitative findings highlight

328 the importance of women's prior knowledge from previous pregnancies. Women in lower-income groups were also

329 more likely to think getting their baby vaccinated during COVID-19 was less important.

330 Our findings are consistent with studies prior to the pandemic with women living in poorer areas or belonging

331 to an ethnic-minority being less likely to be vaccinated in pregnancy $(15,25,26)$. This is mirrored in uptake of childhood

332 vaccines in the UK, with lower-income and ethnic-minority children less likely to receive their routine vaccinations (25,

333 27, 28). Consistent with the findings by Bell et al., we also observed that women from ethnic minorities were more

334 likely to report physical limitations and feeling unsafe when accessing vaccines for their children during the pandemic

335 (18). Different factors affect ethnic minorities living the UK having lower vaccine uptake including access barriers and

336 vaccine confidence $(27,28)$. However, during COVID-19 the increased risk to ethnic-minority populations has been well

337 publicised (29) and ethnic-minority pregnant women are also more likely to admitted to hospital with COVID-19 (30).

338 Ethnic-minority women may have therefore been more nervous about attending healthcare settings for pregnancy

339 vaccines.

340 We found that more women were vaccinated at hospital antenatal settings during COVID-19 compared to

341 previous pregnancies which supports previous work that antenatal hospital vaccine clinics play a key role in delivering

342 pregnancy vaccines (15) and only $7.5 \%$ of women reported a hospital vaccine appointment being changed. Further

343 evaluation of the impact of antenatally delivered vaccines on uptake, including during COVID-19 is required (14, 31). We 
It is made available under a CC-BY 4.0 International license .

344 also found that where women received pregnancy vaccines varied geographically across the UK nations and regionally.

345 This could reflect variation in pre-existing maternal vaccine service provision prior to the pandemic, changes to services

346 in response to the pandemic or transport variation. Mcquaid et al found that the impact of COVID-19 on routine

347 childhood vaccine uptake varied between UK nations with England reporting a decline and Scotland an increase in

348 childhood vaccine uptake in 2020 (11).

349 We found that public transport use to attend healthcare appointments decreased during COVID-19 and

350 private car use increased, which was most marked in London, which had the highest pre-pandemic use of public

351 transport. The impact of reduced public transport on healthcare access could be greater for people living on lower-

352 incomes and belonging to ethnic minorities who are more likely to have fewer transport options available (32). This

353 could explain why women from ethnic minorities were more likely to report that their physical access to vaccine

354 appointments had been negatively impacted by COVID-19 given the government advice to avoid public transport and

355 also the reduced public transport services available during lockdown.

356 Our findings add to the literature that routine care of pregnant women (10) and children (33), including

357 routine vaccines has been impacted by $\operatorname{COVID-19}(3,12,13,18)$. Most women reported appointments being changed,

358 cancelled and/or postponed, including for pregnancy vaccines and some also experienced being vaccinated later than

359 recommended. In a study of 31 qualitative interviews with pregnant women, Anderson et al. did not find disruption to

360 pregnancy vaccine appointments was a common theme, possibly due to the earlier timing of their interviews, in April

361 and May 2020 (20). Consistent with our qualitative findings however, Anderson et al did report that some women

362 debated the benefits of attending for vaccines in pregnancy versus their risk to COVID-19 exposure (20). They also

363 found that pregnant women at the start of the pandemic were confused about social-distancing guidance (21). In a

364 study looking at the impact of the pandemic on maternity services in general, Sanders et al reported that women felt

365 anxious and confused by the changes to UK maternity services, with only $12.9 \%$ feeling virtual antenatal appointments

366 met their needs and $37.6 \%$ unsure about accessing their GP (34). Similarly a national study of 477 families reported

367 that women giving birth during the pandemic in England experienced poor communication resulting in them feeling

368 anxious (35).

369 Our findings suggest difficulties in accessing vaccination appointments have been a more important barrier for

370 pregnant women during COVID-19 than anti-vaccination sentiments. This is consistent with a pre-pandemic survey on

371 childhood vaccination (28) and work by Edelstein et al which suggested that access is a larger barrier to vaccination

372 than anti-vaccination sentiment (36). Healthcare providers in the UK must ensure that access to vaccine appointments 
It is made available under a CC-BY 4.0 International license .

373 is prioritised during COVID-19 for pregnant women and children (7). Our findings also suggest that COVID-19 made

374 access more difficult for lower-income and ethnic-minority mothers, and therefore may have widened pre-existing

375 inequalities in vaccine uptake $(15,27,28,37)$. Improving vaccine uptake among ethnic-minority and low-income

376 women is paramount now given the inequalities experienced by UK low-income areas and ethnic minorities during

377 COVID-19 (38).

378 Recommendation by a trusted healthcare provider has been found to be a key intervention to improve

379 maternal and childhood vaccine uptake $(15,22,39-41)$. Our findings support this, as women preferred vaccine

380 information from healthcare professionals. Every contact with a pregnant woman should be seen as an opportunity to

381 promote and remind about vaccines for both themselves and their children (28), particularly during the pandemic, and

382 information must be accessible to all women (42).

383 Pregnant women are at greater risk of poor outcomes from COVID-19, and COVID-19 vaccines are

384 recommended for UK pregnant women $(43,44)$. Our previous ly reported findings suggest that women from lower-

385 income households and belonging to ethnic-minority groups are less likely to accept COVID-19 vaccines when pregnant,

386 and therefore reflect existing pregnancy vaccine uptake inequalities (45). It is thus essential to focus on promoting

387 COVID-19 vaccination in pregnancy alongside routine pregnancy vaccines, particularly among ethnic-minority and low-

388 income women.

390 Strengths and Limitations

391 The main strength of this study was the use of multiple methods - the qualitative analysis of the survey and

392 interviews enabled factors behind the quantitative findings to be explored in detail. Our response rate of over 1000 UK

393 women who had been pregnant during the first peak of the COVID-19 pandemic was excellent.

394 The survey included women from across the UK, enabling us to identify differences geographically however the

395 majority of women were from England. Regionally, London and the South-East were overrepresented, but the survey

396 included women with a range of ages and income levels and at different pregnancy gestations and both vaccinated and

397 unvaccinated women. Ethnicity was dichotomised into White ethnicities and all other ethnicities for analysis, as we

398 were underpowered to detect differences between individual ethnicity groups. The timing of the survey is a strength as

399 it took place at a time of uncertainty for pregnant women and the healthcare system. Despite vaccines being prioritised

400 for pregnant women, uptake has decreased since the start of the pandemic (14) and our findings therefore remain 
medRxiv preprint doi: https://doi.org/10.1101/2021.09.14.21263505; this version posted September 17, 2021. The copyright holder for this preprint (which was not certified by peer review) is the author/funder, who has granted medRxiv a license to display the preprint in perpetuity. It is made available under a CC-BY 4.0 International license .

401 timely and relevant. However, repeating the survey now would be beneficial and a larger study may be able to detect

402 additional regional and demographic vaccine service and uptake variation during COVID-19.

403

\section{Conclusion}

405 Access to routine vaccinations for UK pregnant women and their babies was disrupted by COVID-19 and

406 changes to antenatal care created confusion. Pre-existing pregnancy vaccine uptake inequalities may have been

407 exacerbated by the pandemic with pregnant women living in lower-income households and belonging to ethnic

408 minorities being less likely to be vaccinated and experiencing greater barriers to accessing vaccines. Our findings are

409 relevant for the delivery and uptake of COVID-19 vaccines in pregnancy.

410 Vaccination in pregnancy and childhood must be prioritised during the ongoing pandemic. Healthcare services

411 should provide pregnant women with clear, accessible information on the importance of vaccinations and how they can

412 safely access vaccine appointments when pregnant and for their babies. Vaccine services must be equitable to optimise

413 uptake among women from ethnic minorities and lower-income households.

414

\section{Acknowledgements:}

416 We would like to thank all survey and interview participants for their time to provide their views and opinions. Thank

417 you to the Bay Wide, Royal Surrey, Sandwell and West Birmingham, Leicester City, Bradford, Bolton, Central Cheshire,

418 Chester, Bath and North-East Somerset, Swindon and Wiltshire, Royal Free and Kingston Maternity Voices Partnerships

419 who agreed to share the survey via their networks. Mr Toby Clements and Dr Thomas F Rice helped with creation and

420 dissemination of the online survey. Thank you to Myrsini Kaforou for the travel heat maps.

\section{Funding:}

424 This research was partly funded by a grant from the Imperial College COVID-19 Research Fund to BH.

426 HS is funded by National Institute for Health Research (NIHR), doctoral research fellowship award number NIHR300907. 
medRxiv preprint doi: https://doi.org/10.1101/2021.09.14.21263505; this version posted September 17, 2021. The copyright holder for this preprint (which was not certified by peer review) is the author/funder, who has granted medRxiv a license to display the preprint in perpetuity.

It is made available under a CC-BY 4.0 International license.

428 HS, BK and BH declare funding from IMmunising PRegnant women and INfants neTwork (IMPRINT) which is funded by

429 the UK Research and Innovation-Global Challenges Research Fund Networks in Vaccines Research and Development

430 which was co-funded by the Medical Research Council and Biotechnology and Biological Sciences Research Council.

431

432 BK is additionally funded by the MRC (MC_UP_A900/1122, MC_UP_A900/115).

433

434 SBe and SMJ declare funding from the National Institute for Health Research Health Protection Research Unit (NIHR

435 HPRU)) in Immunisation at the London School of Hygiene and Tropical Medicine (LSHTM) in partnership with Public

436 Health England (PHE).

437 The views expressed in this publication are those of the author(s) and not necessarily those of the NIHR, NHS or the UK

438 Department of Health and Social Care or Public Health England.

\section{Conflicts of interest}

$440 \quad$ None declared.

\section{Author Contributions}

442 HS contributed to research question formulation, funding acquisition, research design and carrying out the study, data

443 curation, data analysis, writing original article draft and reviewing and editing.

444 SBa contributed to research question formulation, funding acquisition, design and carrying out the study, data curation,

445 data analysis, writing original article draft and reviewing and editing.

446 SBe contributed to research question formulation, funding acquisition, research design and carrying out the study, data

447 analysis and reviewing and editing final article.

448 LR contributed to research design and carrying out the study, data analysis and reviewing and editing final article.

449 SMJ contributed to research question formulation, funding acquisition, research design and reviewing and editing final

450 article.

451 BK contributed to research question formulation, funding acquisition, research design and reviewing and editing final 452 article. 
$453 \mathrm{BH}$ contributed to research question formulation, funding acquisition, research design and carrying out the study, data

454 curation, data analysis, writing original article draft and reviewing and editing.

$B H, L R, H S$ and SBa have verified the underlying data.

Data statement

457 All data supporting this research publication is included in the manuscript and supplementary material.

1. WHO. Carolina Danovaro, Santosh Gurung, Lee Lee Ho, and Ann Lindstrand, Understanding the 462 disruption to programmes through rapid polling 2020 [Available from: 463 https://www.who.int/immunization/GIN_March-April 2020.pdf?ua=1.

4642 Dinleyici EC, Borrow R, Safadi MAP, Damme Pv, Munoz FM. Vaccines and routine immunization 465 strategies during the COVID-19 pandemic. human vaccines \& immunotherapeutics. 2020:1-8.

466 3. Saso A, Skirrow H, Kampmann B. Impact of COVID-19 on Immunization Services for Maternal and 467 Infant Vaccines: Results of a Survey Conducted by Imprint-The Immunising Pregnant Women and Infants 468 Network. Vaccines (Basel). 2020;8(3):556.

469 4. Middeldorp M, van Lier A, van der Maas N, Veldhuijzen I, Freudenburg W, van Sorge NM, et al. Short term impact of the COVID-19 pandemic on incidence of vaccine preventable diseases and participation in routine infant vaccinations in the Netherlands in the period March-September 2020. Vaccine. 2021;39(7):1039-43.

473 5. Schmid-Küpke NK, Matysiak-Klose D, Siedler A, Felgendreff L, Wieler L, Thaiss HM, et al. Cancelled 474 routine vaccination appointments due to COVID-19 pandemic in Germany. Vaccine: X. 2021;8:100094.

475 6. Causey K, Fullman N, Sorensen RJD, Galles NC, Zheng P, Aravkin A, et al. Estimating global and 476 regional disruptions to routine childhood vaccine coverage during the COVID-19 pandemic in 2020: a modelling study. The Lancet. 2021;398(10299):522-34.

480 8. RCGP. Royal College of General Practitioners Guidance on workload prioritisation during COVID-19. 481 Version 8. 10 April 20. 2020 [Available from: https://www.rcgp.org.uk/-/media/Files/Policy/A-Zpolicy/2020/covid19/RCGP-

484 9. Majeed A, Maile EJ, Bindman AB. The primary care response to COVID-19 in England's National Health Service. Journal of the Royal Society of Medicine. 2020;113(6):208-10. the UK during the coronavirus disease 2019 pandemic: a national survey of modifications to standard care. BJOG: An International Journal of Obstetrics \& Gynaecology. 2021;128(5):880-9. pre-school immunisations in Scotland and England during the COVID-19 pandemic: an observational study of routinely collected data. medRxiv. 2021:2021.07.19.21260770.

493 coronavirus disease (COVID-19) pandemic and physical distancing measures on routine childhood 494 vaccinations in England, January to April 2020. Eurosurveillance. 2020;25(19):2000848. 
13. PHE. Public Health England. Impact of COV1ID-19 on childhood vaccination counts to week 9 in 2021, and vaccine coverage to January 2021 In England: interim analyses. Health Protection Report. Volume 15

497 Number 5

499 https://assets.publishing.service.gov.uk/government/uploads/system/uploads/attachment data/file/96776

$500 \quad$ 2/hpr0521 chldhd-vc wk9.pdf.

501 14. PHE. Pertussis vaccination programme for pregnant women update: vaccine coverage in England, 502 January to March 2021 and 2020 to 2021 annual coverage 8 June 2021 [Available from: https://assets.publishing.service.gov.uk/government/uploads/system/uploads/attachment data/file/99235 1/hpr0921 prtsss-vc v4.pdf.

505 15. Skirrow H, Holder B, Meinel A, Narh E, Donaldson B, Bosanquet A, et al. Evaluation of a midwife-led, 506 hospital based vaccination service for pregnant women. Human Vaccines \& Immunotherapeutics. 2020:1-10. 16. Mansfield KE, Mathur R, Tazare J, Henderson AD, Mulick AR, Carreira H, et al. Indirect acute effects

508 of the COVID-19 pandemic on physical and mental health in the UK: a population-based study. The Lancet Digital Health. 2021;3(4):e217-e30.

510 17. Skirrow H, Flynn C, Heller A, Heffernan C, Mounier-Jack S, Chantler T. Delivering routine immunisations in London during the Covid-19 pandemic: lessons for future vaccine delivery. BJGP Open. 2021:BJGPO.2021.0021.

18. Bell S, Clarke R, Paterson P, Mounier-Jack S. Parents' and guardians' views and experiences of accessing routine childhood vaccinations during the coronavirus (COVID-19) pandemic: A mixed-methods study in England. PLOS ONE 2020;15(12):e0244049.

19. NHS. Pregnancy and coronavirus 2021 [Available from: https://www.nhs.uk/conditions/coronaviruscovid-19/people-at-higher-risk/pregnancy-and-coronavirus/.

20. Anderson E, Brigden A, Davies A, Shepherd E, Ingram J. Maternal vaccines during the Covid-19 pandemic:A qualitative interview study with UK pregnant women. Midwifery. 2021:103062.

21. Anderson E, Brigden A, Davies A, Shepherd E, Ingram J. Pregnant women's experiences of social distancing behavioural guidelines during the Covid-19 pandemic 'lockdown' in the UK, a qualitative interview study. BMC Public Health. 2021;21(1):1202.

22. Donaldson B, Jain P, Holder BS, Lindsey B, Regan L, Kampmann B. What determines uptake of pertussis vaccine in pregnancy? A cross sectional survey in an ethnically diverse population of pregnant women in London. Vaccine. 2015;33(43):5822-8.

\section{MaternityVoices. National Maternity Voices Partnership 2021 [Available from:} http://nationalmaternityvoices.org.uk/.

24. Clarke V, Braun V. Thematic analysis. Encyclopedia of critical psychology: Springer; 2014. p. 1947-52. 25. Byrne L, Ward C, White JM, Amirthalingam G, Edelstein M. Predictors of coverage of the national 530 maternal pertussis and infant rotavirus vaccination programmes in England. Epidemiology and Infection. 531 2018;146(2):197-206.

532 26. McAuslane H, Utsi L, Wensley A, Coole L. Inequalities in maternal pertussis vaccination uptake: a 533 cross-sectional survey of maternity units. Journal of Public Health. 2018;40(1):121-8.

534 27. Forster AS, Rockliffe L, Chorley AJ, Marlow LAV, Bedford H, Smith SG, et al. Ethnicity-specific factors 535 influencing childhood immunisation decisions among Black and Asian Minority Ethnic groups in the UK: a 536 systematic review of qualitative research. Journal of Epidemiology and Community Health. 2017;71(6):544.

537 28. RSPH. Royal Society for Public Health. Moving The Needle. Promoting vaccination uptake across the 538 life course.; 2019.

539 29. BBC. BAME coronavirus deaths: What's the risk for ethnic minorities? 2020 [Available from: 540 https://www.bbc.co.uk/news/av/explainers-52969054.

541 30. Knight M, Bunch K, Vousden N, Morris E, Simpson N, Gale C, et al. Characteristics and outcomes of 542 pregnant women admitted to hospital with confirmed SARS-CoV-2 infection in UK: national population based 543 cohort study. BMJ. 2020;369:m2107.

544 31. Llamas A, Amirthalingam G, Andrews N, Edelstein M. Delivering prenatal pertussis vaccine through 545 maternity services in England: What is the impact on vaccine coverage? Vaccine. 2020;38(33):5332-6. 
546 32. NatCen GS, Gogescu F, Grollman C, Cooper E, Khambhaita P. . NatCen Social Research. Transport and 547 inequality: An evidence review for the Department for Transport. 2019 [Available from: 548 https://assets.publishing.service.gov.uk/government/uploads/system/uploads/attachment data/file/95395

$549 \quad 1 /$ Transport and inequality report document.pdf.

550 33. Williams TC, MacRae C, Swann OV, Haseeb H, Cunningham S, Davies P, et al. Indirect effects of the 551 COVID-19 pandemic on paediatric healthcare use and severe disease: a retrospective national cohort study. 552 Archives of Disease in Childhood. 2021:archdischild-2020-321008.

553 34. Sanders J, Blaylock R. "Anxious and traumatised": Users' experiences of maternity care in the UK 554 during the COVID-19 pandemic. Midwifery. 2021;102:103069.

555 35. Aydin E, Glasgow KA, Weiss SM, Khan Z, Austin T, Johnson MH, et al. Giving birth in a Pandemic: 556 Women's Birth Experiences in England during COVID-19. medRxiv. 2021:2021.07.05.21260022.

557 36. Edelstein $M$, Müller M, Ladhani S, Yarwood J, Salathé $M$, Ramsay $M$. Keep calm and carry on 558 vaccinating: Is anti-vaccination sentiment contributing to declining vaccine coverage in England? Vaccine. 559 2020;38(33):5297-304.

$56037 . \quad$ Tiley KS WJ, Andrews N, Ramsay M, Edelstein M. . Inequalities in childhood vaccination timing and 561 completion in London. Vaccine. 2018;36(45):6726-35.

562 38. Marmot M, Allen J. COVID-19: exposing and amplifying inequalities. J Epidemiol Community Health. $563 \quad 2020 ; 74(9): 681-2$.

564 39. Wilson RJ, Paterson P, Jarrett C, Larson HJ. Understanding factors influencing vaccination acceptance 565 during pregnancy globally: a literature review. Vaccine. 2015;33(47):6420-9.

566 40. Wilson R, Paterson P, Larson HJ. Strategies to improve maternal vaccination acceptance. BMC Public 567 Health. 2019;19(1):342.

568 41. Leask J, Kinnersley P, Jackson C, Cheater F, Bedford H, Rowles G. Communicating with parents about 569 vaccination: a framework for health professionals. BMC Pediatrics. 2012;12(1):154.

570 42. SAGE. Factors influencing COVID-19 vaccine uptake among minority ethnic groups. Paper prepared 571 by the ethnicity sub-group of the Scientific Advisory Group for Emergencies (SAGE). Published January. 2021

572 [Available from: https://www.gov.uk/government/publications/factors-influencing-covid-19-vaccine-uptake-

573 among-minority-ethnic-groups-17-december-2020.

574 43. JCVI. Joint Committee on Vaccination and Immunisation. JCVI issues new advice on COVID-19

575 vaccination for pregnant women $16 \mathrm{Apr} 2021$ [Available from: https://www.gov.uk/government/news/icvi-

576 issues-new-advice-on-covid-19-vaccination-for-pregnant-women.

$57744 . \quad$ RCOG. Coronavirus (COVID-19)Vaccination in Pregnancy. Information for healthcare professionals.

578 Royal College Obstetricians and Gynaecologists 2021 [Available from:

579 https://www.rcog.org.uk/globalassets/documents/guidelines/2021-06-30-coronavirus-covid-19-vaccination580 in-pregnancy.pdf.

581 45. Skirrow H, Barnett S, Bell SL, Riaposova L, Mounier-Jack S, Kampmann B, et al. Women's views on 582 accepting COVID-19 vaccination during and after pregnancy, and for their babies: A multi-methods study in 583 the UK. medRxiv. 2021:2021.04.30.21256240. 
medRxiv preprint doi: https://doi.org/10.1101/2021.09.14.21263505; this version posted September 17, 2021. The copyright holder for this preprint (which was not certified by peer review) is the author/funder, who has granted medRxiv a license to display the preprint in perpetuity.

It is made available under a CC-BY 4.0 International license .

586 
medRxiv preprint doi: https://doi.org/10.1101/2021.09.14.21263505; this version posted September 17, 2021. The copyright holder for this preprint (which was not certified by peer review) is the author/funder, who has granted medRxiv a license to display the preprint in perpetuity.

It is made available under a CC-BY 4.0 International license . 
A

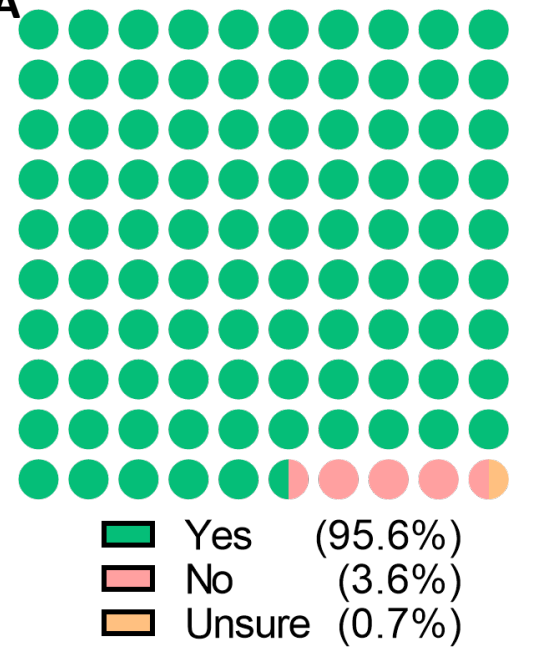

B

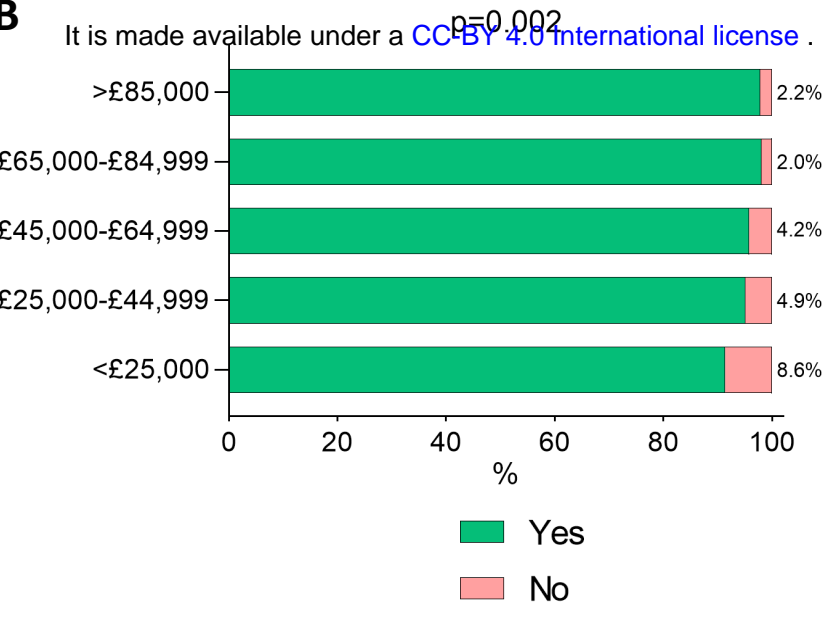

Figure 1: Awareness that pertussis vaccination is recommended in pregnancy during the COVID-19 pandemic. Participants were asked the question: 'Whooping cough vaccine (also known as pertussis or Tdap) is recommended to all pregnant people in the UK. Were you aware of this?'. Possible answers were: 'Yes', 'No' or 'Unsure'. A) Awareness among all survey respondents at the time of survey completion (both women who were currently pregnant and new mothers). B) Awareness of respondents separated by income bracket. Chi-Square Test of association between annual household income and pertussis vaccine awareness; $p=<0.002$. 
preprint (which was not certifled by peer review) is the author/funder, who has granted medRxiv a license to display the preprint in perp

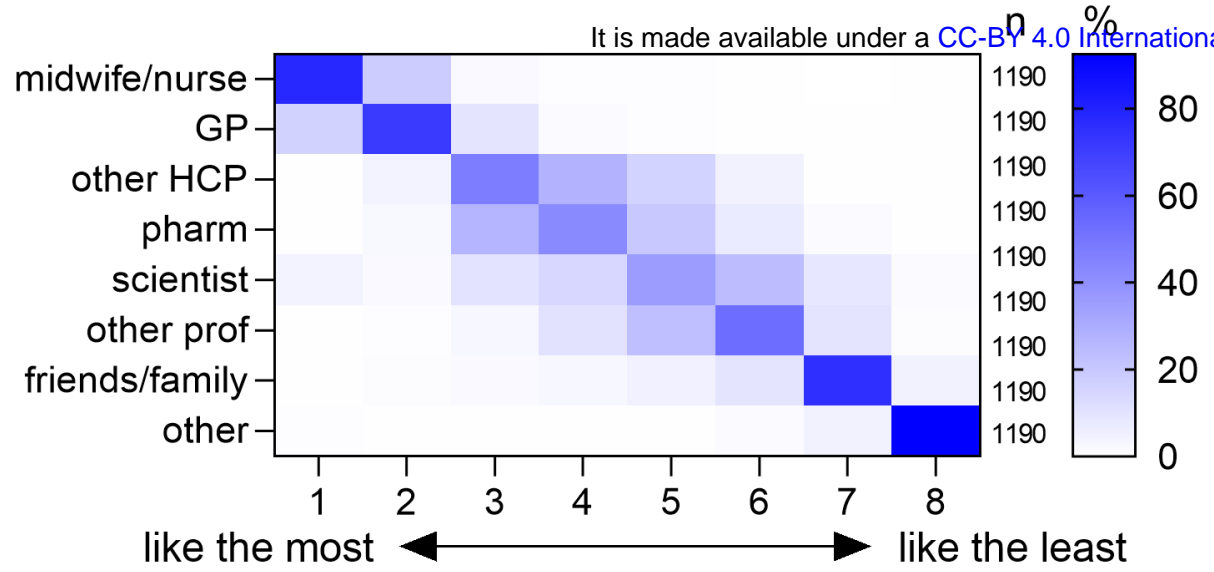

B

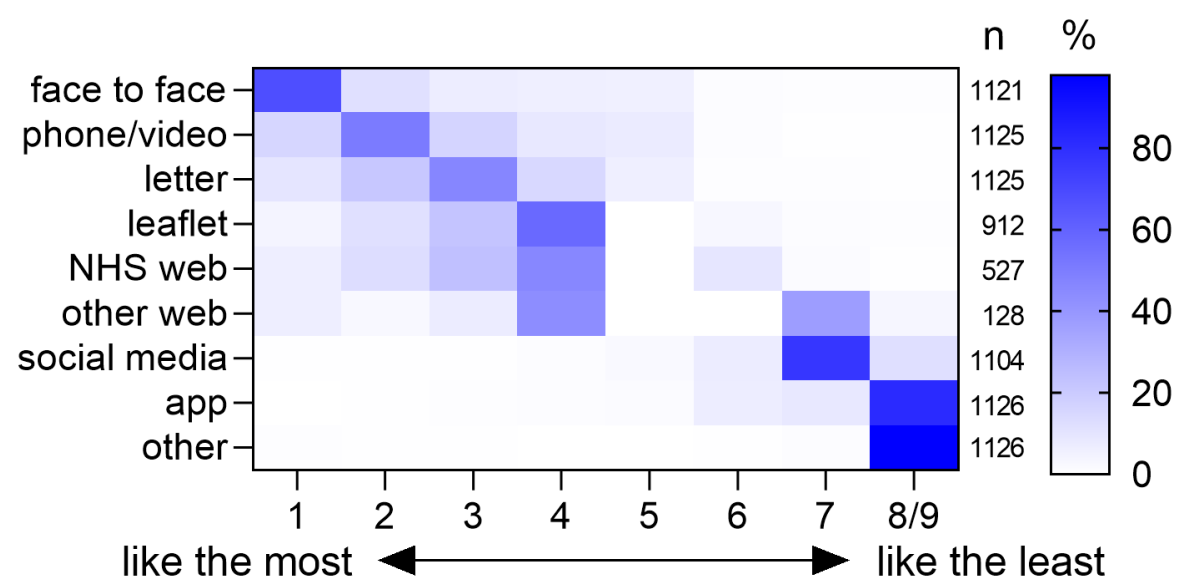

Figure 2: Preferred information sources regarding vaccination in pregnancy during the COVID-19 pandemic. A) The question posed was 'Who would you like to get information from about vaccinations in pregnancy during the coronavirus pandemic?' and respondents asked to rank the listed options from the one they liked the most (1) to the one they liked the least (8). B) The question posed was 'How would you like to get information from about vaccinations in pregnancy during the coronavirus pandemic?' and respondents asked to rank the options from the one they liked the most (1) to the one they liked the least (9). GP; general practitioner, other HCP; other healthcare professional, other prof; other professional; web; website 
It is made available under a CC-BY 4.0 International license

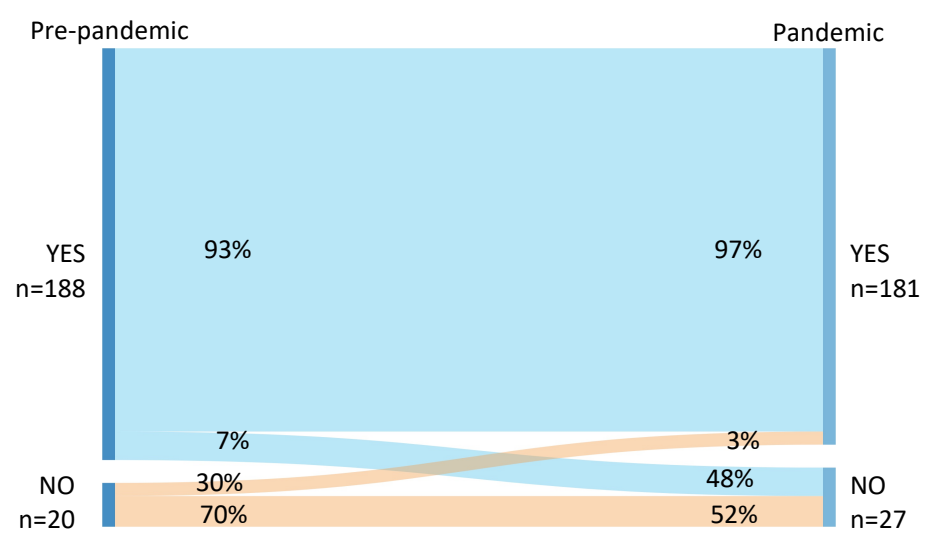

Figure 3: Pertussis vaccination uptake in pregnancies during the COVID-19 pandemic compared to pre-pandemic pregnancies. Sankey plot showing pertussis vaccination uptake in women who had been previously pregnant in the last eight years (left; pre-pandemic), compared to their pregnancy during the pandemic (right). $n=208$. Diagram created using SankeyMATIC. 
Bnder a CC-BY 4.0 International license
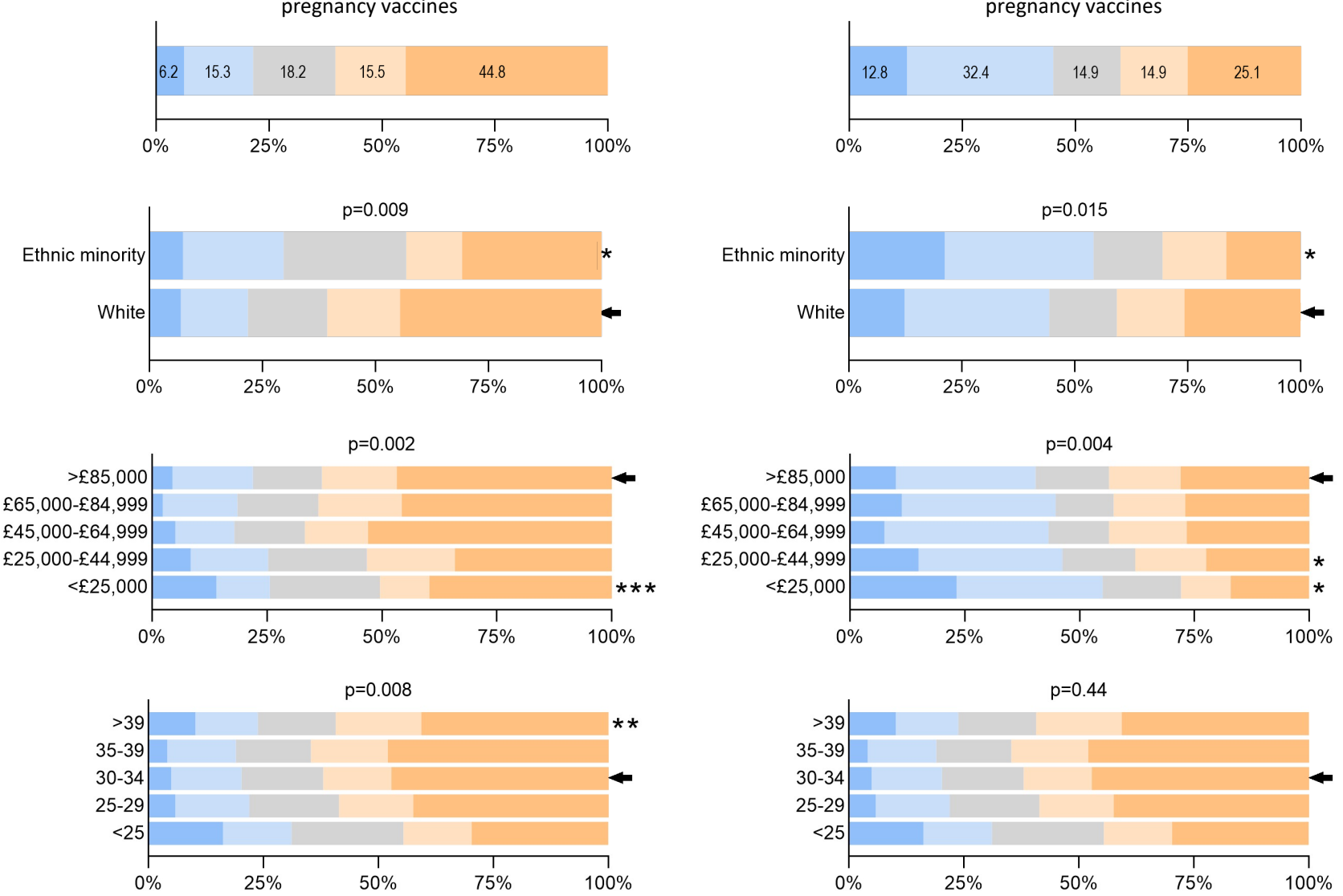

Figure 4. Perceptions of physical restriction and safety when attending for vaccination during pregnancy. $A$ ) Women were asked to what extent they agreed with the following statement : "The COVID pandemic has restricted my physical access to vaccines during pregnancy", and to record this on a Likert scale (see key). The top plot shows all respondents $(n=1,191)$. The lower plots shows responses by ethnicity (with respondents separated into ethnic minority $(n=81)$ and white ethnicity ( $n=929$ ) groups), by income and by age. B) Women were asked to what extent they agreed with the following statement: "The COVID pandemic has restricted my physical access to vaccines during pregnancy" and to record this on a Likert scale (see key). The top plot shows all respondents $(n=1,249)$. The lower plots shows responses by ethnicity (with respondents separated into ethnic minority $(n=81)$ and white ethnicity ( $n=929)$ groups), by income and by age. Differences were analysed using ordered logistic regression. The comparator group is indicated by the arrow, and significant differences indicated with asterisks. ${ }^{*} p<0.05$, ** $p<0.01,{ }^{* * *} p<0.001$. 
it will be physically difficult to vaccinate baby

I feel it's important to vaccinate baby

I feel it's safe to go vaccinate baby

$$
0 \%
$$

B

The pandemic restricted/will restrict physical access to pregnancy vaccines and baby vaccines

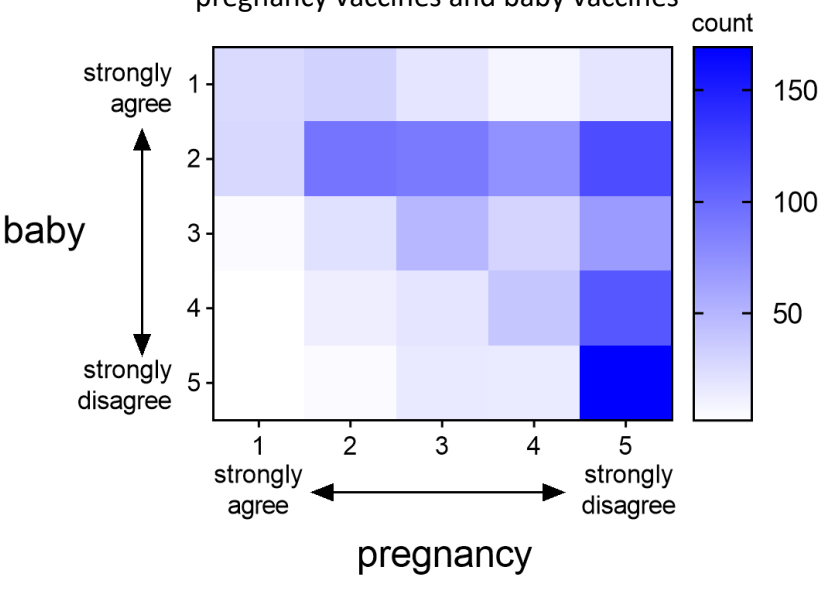

C
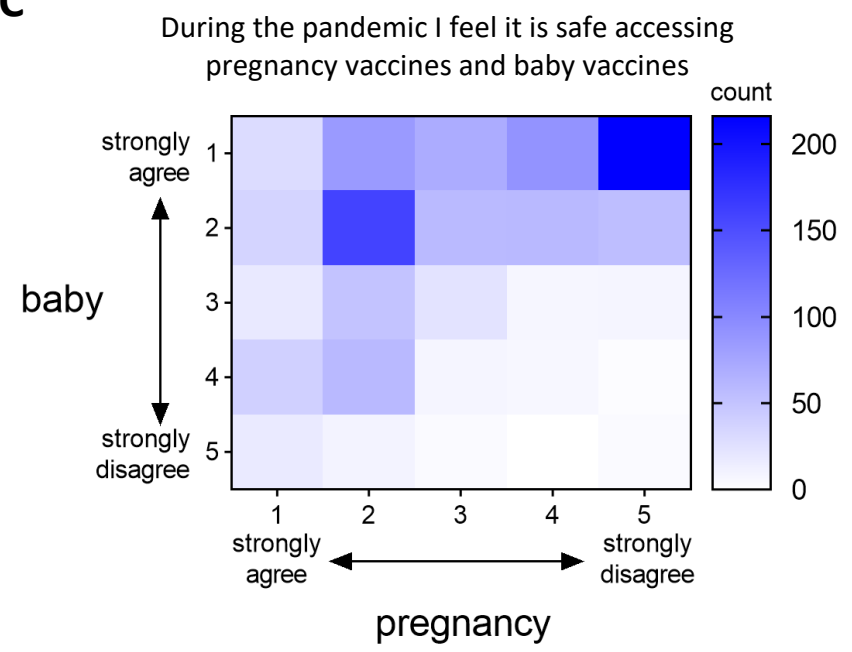

strongly agree

somewhat agree

neither agree nor disagree

somewhat disagree

strongly disagree

Figure 5: Women's perceptions of physical restriction, importance, and safety regarding attending vaccination appointments for their babies, compared to during pregnancy. $A$ : Women were asked to what extent they agreed with the following statements, recording their responses on a Likert scale: 'The COVID-19 pandemic will make it physically difficult to get my baby vaccinated', 'During the COVID-19 pandemic I feel it is important to get my baby vaccinated' and 'During the COVID-19 pandemic I feel it is safe about to go to get my baby vaccinated". B) Heat map showing the relationship between women's perceptions of COVID-19 making it physically difficult to get vaccinated during pregnancy (columns) compared to it making it physically difficult to get their baby vaccinated (rows). C) Heat map showing the relationship between feeling safe accessing pregnancy vaccines during the COVID-19 pandemic (columns) and feeling safe getting baby vaccinated during the COVID-19 pandemic (rows). 1: strongly disagree. 2: somewhat disagree, 3: neither agree nor disagree, 4: somewhat agree, 5: strongly agree. 
medRxiv preprint doi: https://doi.org/10.1101/2021.09.14.21263505; this version posted September 17, 2021. The copyright holder for this preprint (which was not certified by peer review) is the author/funder, who has granted medRxiv a license to display the preprint in perpetuity.

It is made available under a CC-BY 4.0 International license .

\section{Main Paper Tables}

Table 1: Interview and freetext responses illustrating themes

Table 2: Awareness of pertussis vaccine being recommended in pregnancy in the UK

Table 3: Predictors of pertussis vaccine uptake in pregnancy 4

Table 4: Multivariate analysis of predictors of pertussis vaccine uptake 5

Table 5: Appointment changes during COVID-19 pandemic 5

Table 6: Multivariate analysis of predictors of attitudes to accessing to baby vaccinations 6 
Table 1: Interview and free text responses illustrating themes

Theme

- Awareness of vaccinations in pregnancy due to previous pregnancies

- Women's own agency/ability and time to persist in makin vaccine appointm ents.

- Physical access: Disruption of normal hospital and GP services due to COVID-19 an difficulties booking vaccines. Lack of face-to-face

- Lack of clear information on vaccines in pregnancy durin opportunity to ask quest ask questions.

- Understanding the importance of vaccines in pregnancy during the pandemich

Trust in vaccine programmes, NHS and health system advice - due to COVID-19

\section{lustrative quotations from Interviews / Free text responses}

"It is a good job I have been pregnant before and understoodI required the whooping cough. My midwife has given me no communication let alone care "

"I think I was 38 weeks pregnant by the time I'd remem bered about it. And obviously the onus is on me because it was my vaccination but I thought "Oh God, I should probably have that before she arrives". And yeah, so they said "Well we can get you in as you are, you know, heavily pregnant now, we can get you in soon ish". And so, yeah, they booked me in for an appointm ent in the next village along"

"I really had to push for my whooping cough vaccine and it wasn't really mentioned to me it was from a previous pregnancy. I haven't been explicitly told to get the flu jab either."

"I think that I made probably four attempts to try and book it and sort of I was thwarted at every stage"

"got conflicting advice about wherel could get the whooping cough vaccine. My midwife told me to call my doctor and my doctor said they weren't doing them. After quite a lot of attempts to contact various settings I managed to book it through the hospital and have it in a comm unity setting although it was later than the recommended time for the vaccine to work effectively."

"And I did ask for it plenty of times and nobody really got back to me about it except because I had my antenatal and I was face-to-face with them. Then they said "Oh OK, you should just go here and get it". "But when I phoned in, they kind of said "Oh don't worry, we'll arrange it" or "We'll get somebody to call you", so it seem ed like it wasn't really necessary"

"My midwife said I would not be getting due to covid $19 "$

Being told during lockdown to not leave my house unless absolutely care at the clinic i was already in seem ed unnecessarily dangerous"

"appointments were on the phone or then when you did have to go in, you had to like follow strict procedures. So veah it was actually quite stressfyl to be honest"

Vaccinations seemed like an afterthought, I was given almost all of my vaccinations later than I was originally told that I would receive them. I was told I would receive a flu jab as it was coming to the end of the flu season and didn't receive it"

"I feel that anything including vaccines is now plaving second fiddle to anything Covid1 9 related. It seems like if you need something that isn't covid1 9 related, you're complaining about nothing as bad beccuse "could be worse."

"I had my whooping cough vaccine at a 'drive thru' outside the gp surgery.

"Communication with healthcare professionals (midwives/gp/antenatal) has been awful during this pregnancy compared to 4 years ago. A midwife briefly mentioned the whooping cough vaccine to me, didn't "explain anything to me. This wasn't even my midwife, she's not told me about it. I feel several things have not been communicated and missed this time. Pregntor dun "It has never been mentioned by anyone and I now feel extremely anxious that I'm running out of time to get my vaccinations, particularly whooping cough."

"Due to rushed appointments and lack of care from midwives I feel I wasn't given enough information. Luckily I have a scientific background and was a ble to access resources to look into it myself

"I don't know to what extent this is worsened by covid-19, but almost all discussions with midwives and doctors are incredibly rushed. I alwaysfeel like I'm holding up other people by asking questions. IfI did ave questions a bout vaccines, I don't feel there would be enough time to go through them properly"

I've always been in favour of vaccines but covid has made me even more so. The benefits far outweigh the risks (allergic reaction etc). The only thing that's made me feel unsafe is going to the hospital for the tdap and being in that environment

"I just feel it (is) important that we are encouraged to have the same vaccinations that we would whether then pandemic was on or not."

"I thought you had to have it, you know, especially in these times. So because they told me in the beginning and I was told twice and everyone else has got it, and because of everything that's going on, I though

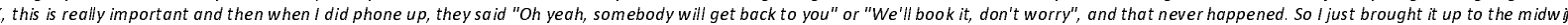

during my antenatal appointment and she said "Oh you can go here to this zone and get it done"

"We're pro vaccination as a family and all other vaccinations seem even more pressing in light of Covid"

"This pandemic had made me less trusting of the medical and political establishment"

"Social media and the media in general, has made me skeptical about vaccines. Scientists have that COVID affects mostly people of black and Asian descent, I am Pakistani. Social media has led me to believe that COVID vaccine amongst others is used to control the black and Asian population and can lead to infertility "4 
medRxiv preprint doi: https://doi.org/10.1101/2021.09.14.21263505; this version posted September 17, 2021. The copyright holder for this preprint (which was not certified by peer review) is the author/funder, who has granted medRxiv a license to display the preprint in perpetuity.

It is made available under a CC-BY 4.0 International license .

Table 2: Awareness of pertussis vaccine being recommended in pregnancy in the UK

\begin{tabular}{|c|c|c|c|}
\hline \multicolumn{4}{|c|}{$\begin{array}{l}\text { Whooping cough vaccine (also known as pertussis or Tdap) is recommended to all pregnant people in the UK. Were } \\
\text { you aware of this? }\end{array}$} \\
\hline & $\begin{array}{c}\text { YES } \\
\text { n (\%) }\end{array}$ & $\begin{array}{c}\text { NO } \\
\text { n (\%) }\end{array}$ & $\begin{array}{l}\text { Chi square test of } \\
\text { independence }\end{array}$ \\
\hline All women & $1,338(95.6)$ & $61(4.4)$ & - \\
\hline \multicolumn{4}{|l|}{ Ethnicity } \\
\hline $\begin{array}{l}\text { White } \\
\text { Minority ethnicity }\end{array}$ & $\begin{array}{l}1,019(95.5) \\
101(93.5)\end{array}$ & $\begin{array}{l}48(4.5) \\
7(6.5)\end{array}$ & $\begin{array}{l}x^{2}=0.86 \\
p=0.353\end{array}$ \\
\hline \multicolumn{4}{|l|}{ Income } \\
\hline Under $£ 24,999$ & $137(89.5)$ & $16(10.5)$ & \\
\hline$£ 25,000-£ 44,999$ & $250(95.1)$ & $13(4.9)$ & \\
\hline$f 45,000-f 64,999$ & $339(95.8)$ & $15(4.2)$ & $x^{2}=20.13$ \\
\hline$£ 65,000-£ 84,999$ & 239 (97.9) & $5(2.1)$ & $p=<0.001$ \\
\hline Over $£ 85,000$ & $261(97.8)$ & $6(2.2)$ & \\
\hline \multicolumn{4}{|l|}{ Age } \\
\hline Under $25 y$ & $84(92.1)$ & $7(7.7)$ & \\
\hline $25-29 y$ & $334(96.5)$ & $12(3.5)$ & \\
\hline $30-34 y$ & $524(95.8)$ & $22(4.0)$ & $x^{2}=6.22$ \\
\hline $35-39 y$ & $292(96.1)$ & $12(3.9)$ & $p=0.183$ \\
\hline Over $39 y$ & $65(91.6)$ & $6(8.4)$ & \\
\hline \multicolumn{4}{|l|}{ Country } \\
\hline Scotland & $51(98.1)$ & $1(1.9)$ & \\
\hline Wales & $35(94.6)$ & $2(5.4)$ & $x^{2}=2.09$ \\
\hline Northern Ireland & $26(100)$ & $0(0)$ & $p=0.552$ \\
\hline England & $1,226(95.5)$ & $58(4.5)$ & \\
\hline \multicolumn{4}{|l|}{ Region } \\
\hline Greater London & $180(95.2)$ & $9(4.8)$ & \\
\hline East Midlands & 74 (94.9) & $4(5.1)$ & \\
\hline West Midlands & $107(97.3)$ & $3(2.7)$ & \\
\hline North East & $58(98.3)$ & $1(1.7)$ & $x^{2}=9.13$ \\
\hline South East & $224(96.6)$ & $8(3.4)$ & $p=0.332$ \\
\hline South West & $95(91.4)$ & $9(8.6)$ & \\
\hline Yorkshire and the Humber & $209(94.1)$ & $13(5.9)$ & \\
\hline East of England & $109(97.3)$ & $3(2.7)$ & \\
\hline
\end{tabular}

Women were asked the question: 'Whooping cough vaccine (also known as pertussis or Tdap) is recommended to all pregnant people in the UK. Were you aware of this?'. Possible answers were: 'Yes', 'No' or 'Unsure'.

No and unsure combined into NO.

Ethnicity Groups: White: White-British, White-Irish, White-Other; Minority ethnicity: Black-British African, Black-British Caribbean and Black-Other, Asian Indian, Asian-Pakistani, Asian-Bangladeshi, Asian-Other and Chinese, Mixed White-Black Caribbean, Mixed White-Black African, Mixed White-Asian, Mixed White/Other and Other ethnicity. 
medRxiv preprint doi: https://doi.org/10.1101/2021.09.14.21263505; this version posted September 17, 2021. The copyright holder for this preprint (which was not certified by peer review) is the author/funder, who has granted medRxiv a license to display the preprint in perpetuity.

It is made available under a CC-BY 4.0 International license .

Table 3: Predictors of pertussis vaccine uptake in pregnancy

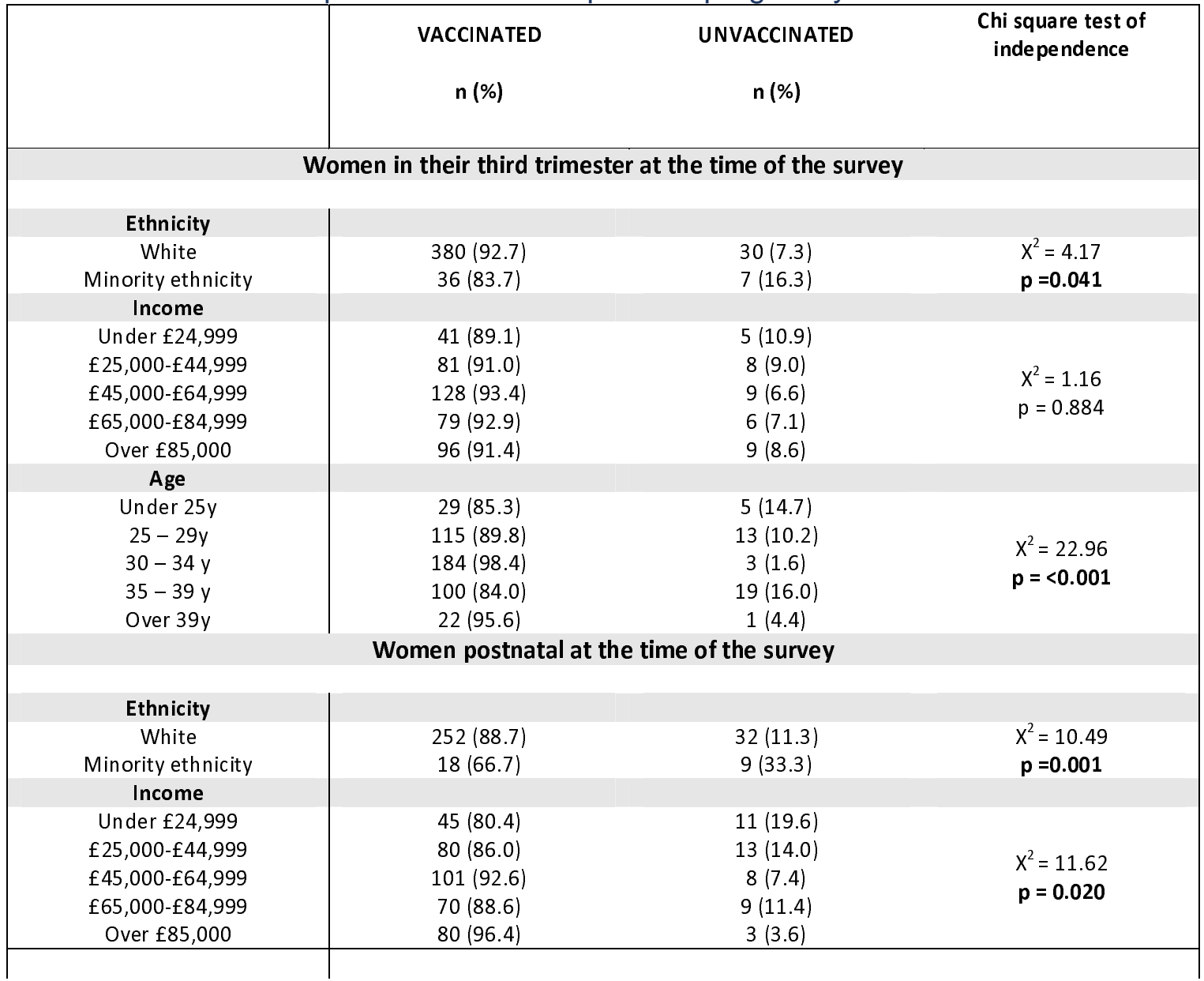

Ethnicity Groups: White: White-British, White-Irish, White-Other; Minority ethnicity: Black-British African, Black-British Caribbean and Black-Other, Asian Indian, Asian-Pakistani, Asian-Bangladeshi, Asian-Other and Chinese, Mixed White-Black Caribbean, Mixed White-Black African, Mixed White-Asian, Mixed White/Other and Other ethnicity. 
medRxiv preprint doi: https://doi.org/10.1101/2021.09.14.21263505; this version posted September 17, 2021. The copyright holder for this preprint (which was not certified by peer review) is the author/funder, who has granted medRxiv a license to display the preprint in perpetuity.

It is made available under a CC-BY 4.0 International license .

Table 4: Multivariate analysis of predictors of pertussis vaccine uptake

\begin{tabular}{|c|c|c|c|c|c|c|}
\hline \multirow{2}{*}{ Variable } & \multicolumn{3}{|c|}{ Pregnant at time of survey } & \multicolumn{3}{|c|}{ Delivered at the time of survey } \\
\hline & OR & $95 \% \mathrm{Cl}$ & $P$ value & OR & $95 \% \mathrm{Cl}$ & $P$ value \\
\hline Ethnicity & & & & & & \\
\hline White\# & - & & - & - & - & - \\
\hline $\begin{array}{c}\text { Minority ethnicity } \\
\text { Age }\end{array}$ & 2.26 & $0.82,6.25$ & 0.116 & 8.33 & $2.53,27.49$ & $<0.001$ \\
\hline Under 25y & 6.23 & $1.13,34.23$ & 0.035 & 1.89 & $0.55,6.50$ & 0.706 \\
\hline $25-29 y$ & 5.26 & $1.34,20.57$ & 0.017 & 0.27 & $0.07,1.03$ & 0.636 \\
\hline $30-34$ y \# & - & 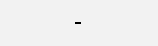 & - & - & - & - \\
\hline $35-39 y$ & 8.79 & $2.45,31.49$ & 0.001 & 0.74 & $0.25,2.19$ & 0.075 \\
\hline $\begin{array}{l}\text { Over 39y } \\
\text { Income }\end{array}$ & 2.21 & $0.21,22.97$ & 0.508 & 1.64 & $0.36,7.48$ & 0.484 \\
\hline Under $£ 24,999$ & 0.77 & $0.19,3.09$ & 0.712 & 7.71 & $1.56,38.16$ & 0.012 \\
\hline$£ 25,000-£ 44,999$ & 0.95 & $0.31,2.90$ & 0.935 & 3.61 & $0.75,17.34$ & 0.109 \\
\hline$£ 45,000-£ 64,999$ & 0.52 & $0.17,1.58$ & 0.249 & 2.65 & $0.51,13.58$ & 0.242 \\
\hline$f 65,000-f 84,999$ & 0.77 & $0.23,2.54$ & 0.671 & 4.01 & $0.84,18.98$ & 0.080 \\
\hline Over $£ 85,000 \#$ & . & - & - & - & - & - \\
\hline
\end{tabular}

OR: ord inal odds ratio. An OR above 1 indicates a higher likelihood of women being unvaccinated in pregnancy. 95\% Cl: 95\% confidence interval. \# indicates the comparator group in the analysis. Ethnicity Groups: White: White-British, White-Irish, White-Other; Minority ethnicity: Black-British African, Black-British Caribbean and Black-Other, Asian Indian, Asian-Pakistani, Asian-Bangladeshi, Asian-Other and Chinese, Mixed White-Black Caribbean, Mixed White-Black African, Mixed White-Asian, Mixed White/Other and Other ethnicity.

Table 5: Appointment changes during COVID-19 pandemic

\begin{tabular}{|cccccc|}
\hline n=1404 & $\begin{array}{c}\text { GP apt } \\
\text { for pregnancy }\end{array}$ & $\begin{array}{c}\text { GP apt } \\
\text { for vaccine }\end{array}$ & GP apt for other & $\begin{array}{c}\text { Hospital apt } \\
\text { for vaccine }\end{array}$ & $\begin{array}{c}\text { Hospital apt } \\
\text { for other }\end{array}$ \\
\hline Postponed by patient & $2.1 \%$ & $1.4 \%$ & $0.8 \%$ & $0.5 \%$ & $1.5 \%$ \\
\hline Postponed by GP/hospital & $10.8 \%$ & $2.8 \%$ & $2.6 \%$ & $2.7 \%$ & $7.3 \%$ \\
\hline Cancelled by patient & $1.1 \%$ & $1.1 \%$ & $0.6 \%$ & $0.6 \%$ & $0.5 \%$ \\
\hline Cancelled by GP/hospital & $16.2 \%$ & $2.6 \%$ & $3.9 \%$ & $2.3 \%$ & $9.1 \%$ \\
\hline Changed to phone/online & $53.3 \%$ & $1.6 \%$ & $33.8 \%$ & $1.7 \%$ & $33.2 \%$ \\
\hline Blank (no disruptions/NA) & 533 & 848 & 1275 & 1298 & 801 \\
\hline Total reports disruptions & $68.8 \%$ & $13.6 \%$ & $31.5 \%$ & $7.7 \%$ & $47.5 \%$ \\
\hline$\%$ patients reporting disruption & $62.0 \%$ & $39.6 \%$ & $9.2 \%$ & $7.5 \%$ & $42.9 \%$ \\
\hline
\end{tabular}

Women were asked 'Have you had any appointments changed due to the COVID-19 pandemic' for the following appointment types. 'An appointment at your GP surgery about your pregnancy, 'An appointment at your GP surgery fto receive a pregnancy vaccine', 'An appointment at your GP for an other reason', 'An appointment at a hospital to receive a pregnancy vaccine' and 'An appointment at the hospital for another reason'. Apt $=$ appointment. 
medRxiv preprint doi: https://doi.org/10.1101/2021.09.14.21263505; this version posted September 17, 2021. The copyright holder for this preprint (which was not certified by peer review) is the author/funder, who has granted medRxiv a license to display the preprint in perpetuity.

It is made available under a CC-BY 4.0 International license .

Table 6: Multivariate analysis of predictors of attitudes to accessing to baby vaccinations

\begin{tabular}{|c|c|c|c|c|c|c|c|c|c|}
\hline \multirow[t]{2}{*}{ Variable } & \multicolumn{3}{|c|}{$\begin{array}{l}\text { The COVID-19 pandemic will } \\
\text { make it physically difficult to get } \\
\text { my baby vaccinated }\end{array}$} & \multicolumn{3}{|c|}{$\begin{array}{l}\text { During the COVID-19 pandemic I } \\
\text { feel it is important to get my baby } \\
\text { vaccinated }\end{array}$} & \multicolumn{3}{|c|}{$\begin{array}{l}\text { During the COVID-19 pandemic I } \\
\text { feel it is safe to go to get my baby } \\
\text { vaccinated }\end{array}$} \\
\hline & OR & $95 \% \mathrm{Cl}$ & $P$ value & OR & $95 \% \mathrm{Cl}$ & $P$ value & OR & $95 \% \mathrm{Cl}$ & $P$ value \\
\hline \multicolumn{10}{|l|}{ Ethnicity } \\
\hline White\# & - & - & - & - & - & - & & & \\
\hline $\begin{array}{c}\text { Minority ethnicity } \\
\text { Age }\end{array}$ & 0.46 & $0.29,0.74$ & 0.001 & 3.41 & $1.95,5.95$ & $<0.001$ & 2.14 & $1.36,3.39$ & 0.001 \\
\hline Under $25 y$ & 0.67 & $0.39,1.16$ & 0.155 & 1.25 & $0.59,2.62$ & 0.550 & 1.69 & $1.00,2.88$ & 0.049 \\
\hline $25-29 y$ & 1.18 & $0.87,1.61$ & 0.281 & 0.99 & $0.58,1.66$ & 0.968 & 0.91 & $0.66,1.25$ & 0.56 \\
\hline $30-34$ y\# & - & - & - & - & - & - & - & - & - \\
\hline $35-39 y$ & 0.98 & $0.72,1.34$ & 0.902 & 0.88 & $0.49,1.54$ & 0.648 & 0.88 & $0.64,1.22$ & 0.46 \\
\hline $\begin{array}{l}\text { Over } 39 y \\
\text { Income }\end{array}$ & 1.14 & $0.67,1.94$ & 0.638 & 1.30 & $0.58,2.95$ & 0.525 & 1.46 & $0.83,2.55$ & 0.19 \\
\hline Under $£ 24,999$ & 1.00 & $0.63,1.59$ & 0.982 & 3.97 & $1.99,7.96$ & $<0.001$ & 1.57 & $0.97,2.52$ & 0.064 \\
\hline$f 25,000-£ 44,999$ & 0.82 & $0.56,1.21$ & 0.327 & 1.96 & $1.02,3.79$ & 0.044 & 1.19 & $0.80,1.79$ & 0.373 \\
\hline$f 45,000-f 64,999$ & 1.14 & $0.80,1.60$ & 0.473 & 0.79 & $0.39,1.62$ & 0.535 & 0.99 & $0.69,1.42$ & 0.963 \\
\hline$f 65,000-f 84,999$ & 1.11 & $0.77,1.59$ & 0.556 & 1.49 & $0.77,2.88$ & 0.234 & 1.2 & $0.84,1.79$ & 0.283 \\
\hline Over $f 85,000 \#$ & - & - & - & - & - & - & - & - & - \\
\hline
\end{tabular}

Women were asked how much they agreed or disagreed with the following statements:

'The COVID-19 pandemic will make it phyiscally difficult to get my baby vaccinated', 'During the COVID-19 pandemic I feel it is important to get my baby vaccinated' and 'During the COVID-19 pandemic I feel it is safe about to go to get my baby vaccinated". Responses were on a scale of Strongly agree, somewhat agree, neither agree nor disagree, somewhat disagree, strongly disagree and not/applicable'.

OR: ordinal odds ratio. An OR above 1 indicates a higher likelihood of women giving responses moving from Strongly agree, somewhat agree, neither agree nor disagree, somewhat disagree, strongly disagree and not/applicable' so are more likely to have disagreed with the statement. $95 \% \mathrm{Cl}: 95 \%$ confidence interval. \# indicates the comparator group in the analysis. Ethnicity Groups: White: White-British, White-Irish, White-Other; Minority ethnicity: Black-British African, BlackBritish Caribbean and Black-Other, Asian Indian, Asian-Pakistani, Asian-Bangladeshi, Asian-Other and Chinese, Mixed White-Black Caribbean, Mixed White-Black African, Mixed White-Asian, Mixed White/Other and Other ethnicity. 